\title{
Clinical effects of cisplatin plus recombinant human endostatin (rh-endostatin) intratumoral injection on malignant central airway obstruction: a retrospective analysis of 319 cases
}

\author{
Yunzhi Zhou, Yongping Gao, Nan Zhang, Xiaoli Li, Hui Wang, Shufang Wang, Jiankun Liu, Hong Gao, \\ Hongwu Wang \\ Department of Respiratory Medicine, Emergency General Hospital, Beijing, China \\ Contributions: (I) Conception and design: H Wang, Y Zhou, Y Gao; (II) Administrative support: H Wang, Y Zhou; (III) Provision of study materials \\ or patients: N Zhang, X Li, H Wang, S Wang, J Liu, H Gao; (IV) Collection and assembly of data: Y Gao, N Zhang, X Li, H Wang, S Wang, J Liu, \\ H Gao; (V) Data analysis and interpretation: Y Zhou, Y Gao; (VI) Manuscript writing: All authors; (VII) Final approval of manuscript: All authors. \\ Correspondence to: Hongwu Wang. Department of Respiratory Medicine, Emergency General Hospital, Beijing 100028, China. \\ Email: wanghongwu2015@126.com.
}

\begin{abstract}
Background: Primary lung cancer with severe central airway obstruction (CAO) is often life-threatening. In this study, we investigated the clinical efficacy and safety of cisplatin plus recombinant human endostatin (rh-endostatin) intratumoral injection in treatment of malignant central airway obstruction (MCAO) caused by primary squamous cell lung cancer.

Methods: We retrospectively analyzed patients with MCAO caused by primary squamous cell lung cancer treated with and without bronchoscopic intratumoral injection of cisplatin plus rh-endostatin between January 2007 and June 2016.

Results: A total of 206 patients received cisplatin plus rh-endostatin intratumoral injection, and 113 without injection. Dyspnea grade, degree of stenosis, quality of life and lung function of all patients were significantly improved at 1 week after treatment compared with baseline. Both groups achieved good airway patency $(97.1 \%$ vs. $93.8 \%, \mathrm{P}=0.156)$. Followed up at 2 months, all parameters were improved in the injection group compared with baseline, while no statistical differences were observed in the non-injection group ( $\mathrm{P}>0.05)$. The injection group achieved airway patency in 155 (75.2\%) of 206 patients, which was significantly superior to the non-injection group [20 (17.7\%) of $113, \mathrm{P}<0.001]$. In addition, the restenosis rate of the injection group was lower compared with the non-injection group $(22.5 \% v s .81 .1 \%, \mathrm{P}<0.001$, respectively). No serious complications were observed in two groups.

Conclusions: Cisplatin plus rh-endostatin intratumoral injection is effective and safe for the therapy of MCAO caused by primary squamous cell lung cancer.
\end{abstract}

Keywords: Cisplatin; recombinant human endostatin; intratumoral injection; lung cancer; airway obstruction

Submitted Mar 27, 2020. Accepted for publication Dec 21, 2020.

doi: $10.21037 /$ jtd-20-1493

View this article at: http://dx.doi.org/10.21037/jtd-20-1493

\section{Introduction}

Lung cancer is the leading cause of morbidity and mortality among malignant tumors (1) with annually increasing prevalence in China $(2,3)$. Primary lung cancer with severe central airway obstruction (CAO) is often life- threatening (4). Treatments with laser, electrocautery, argon plasma coagulation and stent placement via bronchoscopy are effective in reducing airway stenosis caused by malignant central airway tumors $(5,6)$, but the stenosis will recur in a short time (7). Cisplatin intratumoral injection is safe and effective in patients with 
isolated hilar and mediastinal recurrence of lung cancer (8). However, whether cisplatin plus rh-endostatin combined intratumoral injection could be treated in MCAO patients remains unclear. We hypothesized that cisplatin plus rhendostatin intratumoral injection is effective in reducing stenosis and improving dyspnea in MCAO. Thus, we investigated the efficacy and safety of cisplatin plus rhendostatin intratumoral injection in treatment of MCAO caused by primary squamous cell lung cancer.

\section{Methods}

\section{Study population}

We retrospectively reviewed the medical records of all patients treated with and without cisplatin plus rhendostatin intratumoral injection in MCAO caused by primary squamous cell lung cancer at the Emergency General Hospital (Beijing, China) between January 2007 and June 2016. The study was conducted in accordance with the Declaration of Helsinki (as revised in 2013) and informed consent was taken from all the patients.

\section{Intratumoral injection}

Subjects were administered midazolam (1-2 mg) plus sufentanil $(5 \mathrm{mg})$ intravenously for general anesthesia (9). The rigid (STORZ, Germany) and soft bronchoscope (BF260, Olympus Inc., Osaka, Japan) were passed transorally for the treatment. The lesions in the bronchial wall were initially debulked through endobronchial (10). Patients in non-injection group only received interventional bronchoscopy to debulk the lesions and remove debris. Patients in injection group were treated with $20-40 \mathrm{mg}$ of cisplatin (concentration of $5 \mathrm{mg} / \mathrm{mL}$ ) and $15 \mathrm{mg}$ of rhendostatin (Endostar, Shandong Simcere-Medgenn BioPharmaceutical Co., Ltd.) injected directly into the tumor after debulking. Cisplatin and Endostar were administered endoscopically to visible tumor tissue via a flexible 19-gauge Wang needle inserted directly into the tumor's root, including tumor and adjacent tissues. Each injection covered 4-6 sites depending on the size of the tumor. After injection, the bronchoscope was passed distally to the tumor and excess drug was suctioned from the distal airways to prevent the potential for alveolar toxicity secondary to residual drug. To ensure alleviate airway obstruction and increase a greater penetration to tumor, necrotic debris was removed before dosing at visit 2 and thereafter.

\section{Measurements}

The following data were retrospectively obtained from patients' medical records: demographic information, tumor distribution, degree of stenosis, Karnofsky performance scale (KPS) score (11), Eastern Cooperative Oncology Group (ECOG) score (12), dyspnea grade (13) and lung function test. The degree of airway obstruction (14) was initially assessed based on visual estimation by the bronchoscopists. The residual airway obstruction was estimated by visual assessment at 1 week and 2 months after the final dose by the same proceduralists. Expansion more than $50 \%$ ordinary diameter of the bronchus with malignant airway obstruction were accepted as procedure successes, while expansion below $50 \%$ were defined as failures (15). Restenosis was defined as tracheal diameter less than $50 \%$ after treatment. The complications were also evaluated.

\section{Statistical analysis}

Statistical analysis was conducted using SPSS 19.0 (SPSS Inc., Ill, USA). Numeric data were expressed as mean \pm standard deviation, and compared with $t$-test or MannWhitney test. Associations between response rates were conducted by the Pearson's chi-squared test. $\mathrm{P}<0.05$ was deemed statistically significant.

\section{Results}

\section{Patient characteristics}

From January 2007 to June 2016, we treated 319 patients who presented with symptomatic malignant airway obstruction of the trachea and/or major bronchus, histologically confirmed primary squamous cell lung cancer (Figure 1). A total of 206 patients received cisplatin plus Endostar intratumoral injection, and 113 without injection. Lung function was not evaluated in 20 patients due to severe symptoms. No significant differences were observed between the two groups at baseline (Table 1).

\section{Treatment effect}

Dyspnea grade, degree of stenosis, KPS score, ECOG score and lung function of all patients were significantly improved at 1 week after treatment compared with baseline (Table 2, $\mathrm{P}<0.05)$. Both groups achieved good airway patency $(97.1 \%$ 


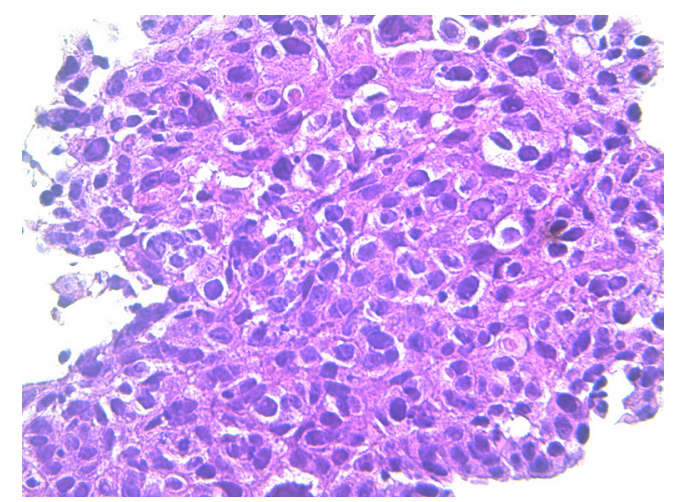

Figure 1 Primary squamous cell carcinoma of the trachea $(\mathrm{HE}$ staining, $\times 400)$. vs. $93.8 \%, \mathrm{P}=0.156)$. There was no statistical difference in all the parameters between the two groups at 1 week $(\mathrm{P}>0.05)$.

Followed up at 2 months, dyspnea grade, degree of stenosis, quality of life and lung function were improved in the injection group compared with baseline $(\mathrm{P}<0.05)$, while no statistical differences were found in the non-injection group $(\mathrm{P}>0.05)$. The injection group achieved airway patency in 155 (75.2\%) of 206 patients (Figure 2), which was significantly superior to the non-injection group [20 (17.7\%) of $113, \mathrm{P}<0.001]$. In addition, the restenosis rate of the injection group was lower compared with the non-injection group (22.5\% vs. $81.1 \%, \mathrm{P}<0.001$, respectively).

Table 1 Patient characteristics

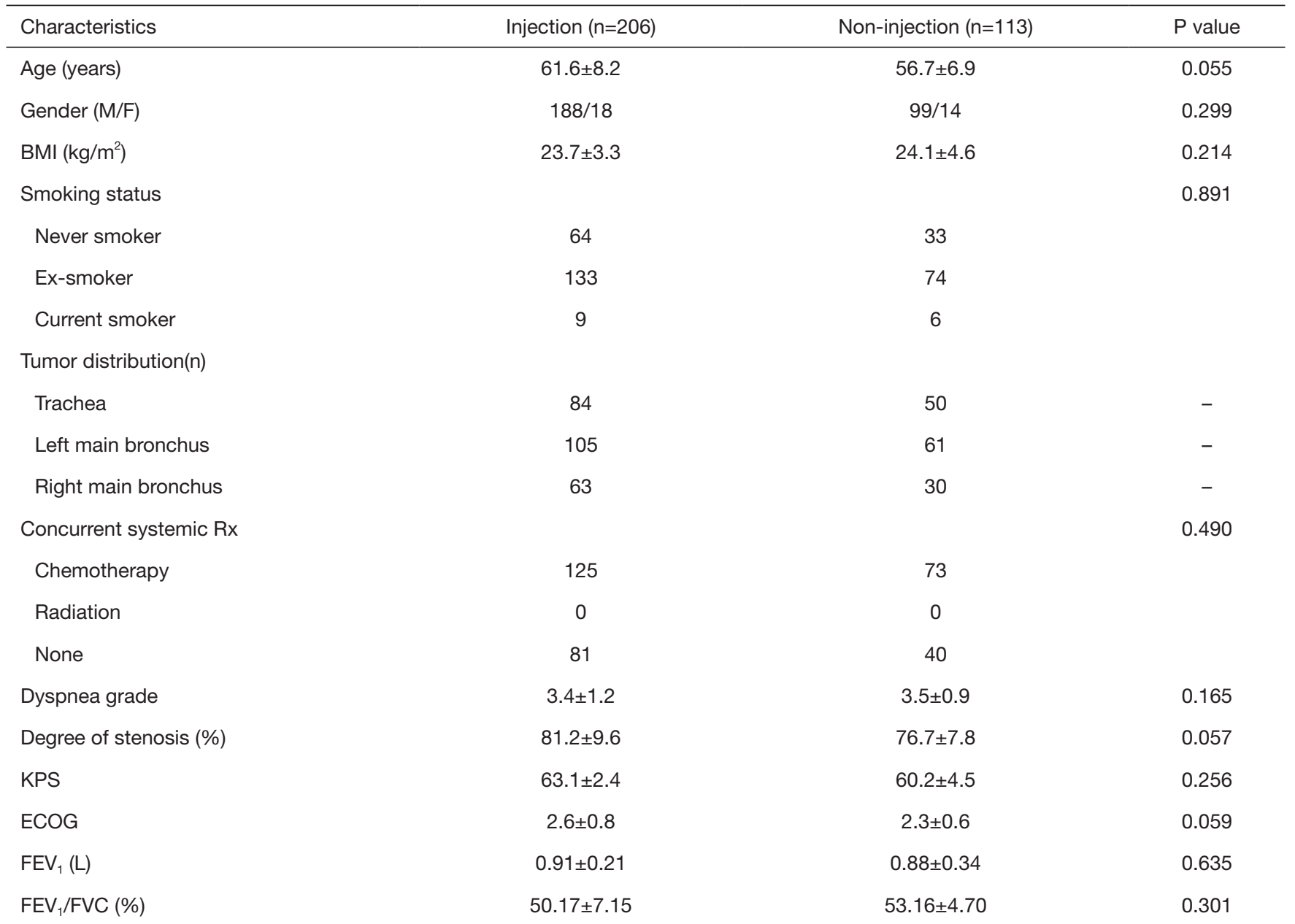

Results are expressed as means \pm standard deviation. FEV $_{1}$, forced expiratory volume in 1 second; FVC, forced vital capacity; KPS, Karnofsky performance scale; ECOG, Eastern Cooperative Oncology Group; BMI, body mass index. 
Table 2 Efficacy at 1 week and 2 months

\begin{tabular}{|c|c|c|c|c|}
\hline Efficacy & \multicolumn{2}{|c|}{ Injection $(n=206)$} & \multicolumn{2}{|c|}{ Non-injection $(n=113)$} \\
\hline Dyspnea grade & $1.1 \pm 0.6$ & $1.5 \pm 0.5$ & $1.3 \pm 0.4$ & $2.9 \pm 0.3$ \\
\hline Degree of stenosis (\%) & $32.2 \pm 5.2$ & $36.4 \pm 7.1$ & $34.1 \pm 3.5$ & $68.7 \pm 3.9$ \\
\hline KPS & $86.3 \pm 6.9$ & $80.4 \pm 3.3$ & $87.1 \pm 3.4$ & $65.5 \pm 2.8$ \\
\hline $\mathrm{FEV}_{1}(\mathrm{~L})$ & $1.35 \pm 0.17$ & $1.26 \pm 0.21$ & $1.37 \pm 0.23$ & $0.98 \pm 0.22$ \\
\hline $\mathrm{FEV}_{1} / \mathrm{FVC}(\%)$ & $59.16 \pm 5.25$ & $57.25 \pm 3.46$ & $58.24 \pm 3.13$ & $53.78 \pm 5.32$ \\
\hline
\end{tabular}

Results are expressed as means \pm standard deviation. FEV $_{1}$, forced expiratory volume in 1 second; FVC, forced vital capacity; KPS, Karnofsky performance scale; ECOG, Eastern Cooperative Oncology Group.
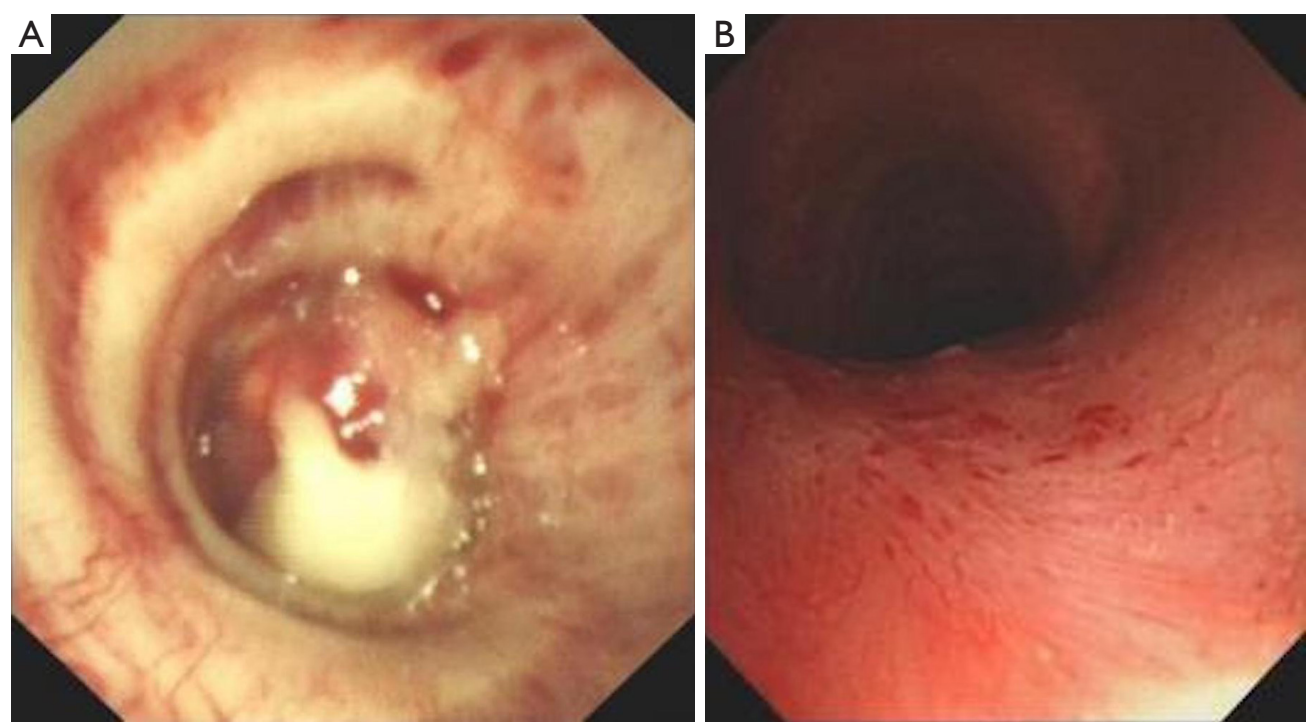

Figure 2 Intratumoral injection of primary squamous cell carcinoma of trachea. (A) Tumor visualization prior to treatment; (B) 2 months after treatment.

Table 3 Complications

\begin{tabular}{lccc}
\hline Complication & Injection $(\mathrm{n}=206)$ & Non-injection $(\mathrm{n}=113)$ & $\mathrm{P}$ value \\
\hline $\begin{array}{l}\text { Mild } \\
\text { hemorrhage }\end{array}$ & $41(19.9)$ & $15(13.3)$ & 0.137 \\
Nausea & $36(17.5)$ & $10(8.8)$ & 0.101 \\
Vomiting & $11(5.3)$ & $8(7.1)$ & 0.530 \\
Lung infection & $2(1.0)$ & $1(0.9)$ & 0.939 \\
Cough & $60(29.1)$ & $41(36.3)$ & 0.189 \\
Fever & $14(6.8)$ & $10(8.8)$ & 0.506 \\
\hline
\end{tabular}

Data presented as $\mathrm{n}(\%)$.

\section{Complications}

There was no statistically significant difference between groups in terms of complications (Table 3). Patients had mild hemorrhage during the endobronchial treatment and were easily stopped by argon and/or cold saline. Gastrointestinal reaction was observed occasionally post treatment, which was improved after a single dose of metoclopramide administered by intramuscular injection. Three patients had lung Infection post treatment and were cured in 7 days. A few patients had transient cough or low fever postprocedure, which were improved significantly in 3 days. No 
local adverse effects such as fistula formation or mediastinal abscess were noted in the follow-up.

\section{Discussion}

Our results indicated that cisplatin plus rh-endostatin intratumoral injection could improve the patency of airways occluded by endobronchial malignant tumor. Cisplatin was commonly used for the treatment of lung cancer as a part of combination systemic chemotherapy (16), and it also had been used intralesionally for head, neck, liver cancers, esophageal cancers and gastric tumors (17-20). The present work confirmed and extended previously reported favorable experience with cisplatin intratumoral injection on lung cancer $(21,22)$. Although Endostar was proved to be effective in treatment of lung cancer combined with another chemotherapy $(23,24)$, there were no reports of MCAO treated with bronchoscopic intratumoral injection of Endostar, let alone combined with cisplatin.

In this study, cisplatin plus Endostar showed a good response in majority of patients. Therapeutic bronchoscopy has been shown to palliate symptoms, improve spirometry, functional capacity, quality of life and survival in patients with MCAO (25-27). Multiple techniques are often used for the recanalization of airway, but the stenosis will recur in 1 to 3 months (7). Our results showed that the rate of restenosis was less in intratumoral injection group when compared with debulking alone. Improvement in clinical benefit parameters supported the therapeutic potential of intratumoral injection and offered another choice for MCAO. Regarding safety, intratumoral injection was also well tolerated. Treatment with intratumoral injection did not increase adverse event.

The main limitation was the retrospective nature of the study, which resulted in selection bias. Furthermore, because of the short follow-up period, the long-term treatment effect was not available. Prospective multicenter randomized trials should be conducted to determine whether intratumoral injection combined with debulking is superior to debulking alone.

\section{Conclusions}

Our findings have highlighted significant therapeutic potential of cisplatin plus rh-endostatin intratumoral injection for MCAO caused by primary squamous cell lung cancer.

\section{Acknowledgments}

Funding: None.

\section{Footnote}

Data Sharing Statement: Available at http://dx.doi. org/10.21037/jtd-20-1493

Conflicts of Interest: All authors have completed the ICMJE uniform disclosure form (available at http://dx.doi. org/10.21037/jtd-20-1493). The authors have no conflicts of interest to declare.

Ethical Statement: The authors are accountable for all aspects of the work in ensuring that questions related to the accuracy or integrity of any part of the work are appropriately investigated and resolved. The study was conducted in accordance with the Declaration of Helsinki (as revised in 2013) and informed consent was taken from all the patients.

Open Access Statement: This is an Open Access article distributed in accordance with the Creative Commons Attribution-NonCommercial-NoDerivs 4.0 International License (CC BY-NC-ND 4.0), which permits the noncommercial replication and distribution of the article with the strict proviso that no changes or edits are made and the original work is properly cited (including links to both the formal publication through the relevant DOI and the license). See: https://creativecommons.org/licenses/by-nc-nd/4.0/.

\section{References}

1. He J, Gu D, Wu X, et al. Major causes of death among men and women in China. N Engl J Med 2005;353:1124-34.

2. She J, Yang P, Hong Q, et al. Lung cancer in China: challenges and interventions. Chest 2013;143:1117-26.

3. Chen $W$, Zheng R, Baade PD, et al. Cancer statistics in China, 2015. CA Cancer J Clin 2016;66:115-32.

4. Wang H, Zhang N, Li D, et al. Analysis of 881 cases of central airway cancer. Chinese Journal of Tuberculosis and Respiratory Diseases 2014;37:148-9.

5. Bolliger CT, Sutedja TG, Strausz J, et al. Therapeutic bronchoscopy with immediate effect: laser, electrocautery, argon plasma coagulation and stents. Eur Respir J 2006;27:1258-71.

6. Wang H, Zhang N, Li D, et al. Zhongguo Fei Ai Za Zhi 
2016;19:854-8.

7. Tao M, Wang H, Zhou Y, et al. Interventional therapy by bronchuscope on trachea adenoid cystic carcinoma in end stage. International Journal of Respiration 2013;33:911-4.

8. Mehta HJ, Jantz MA. Endobronchial Ultrasound-guided Intratumoral Injection of Cisplatin for the Treatment of Isolated Mediastinal Recurrence of Lung Cancer. J Vis Exp 2017;(120):54855.

9. Cheng Q, Li L, Jia D. Anesthesia management of bronchoscope intervention complications. Chinese Journal of Minimally Invasive Surgery 2009;9:954-5.

10. Wang H, Zhou Y, Li D, et al. Clinical application of videoassisted rigid bronchoscopy in the treatment of airway stenosis. Zhongguo Fei Ai Za Zhi 2011;14:367-72.

11. Schag CC, Heinrich RL, Ganz PA. Karnofsky performance status revisited: reliability, validity, and guidelines. J Clin Oncol 1984;2:187-93.

12. Oken MM, Creech RH, Tormey DC, et al. Toxicity and response criteria of the Eastern Cooperative Oncology Group. Am J Clin Oncol 1982;5:649-55.

13. Stulbarg RC, Adams L. Text book of medicine(M). Philadelphia: Saunders, 1994:511-2.

14. Freitag L, Ernst A, Unger M, et al. A proposed classification system of central airway stenosis. Eur Respir J 2007;30:7-12.

15. Kızılgöz D, Aktaş Z, Yılmaz A, et al. Comparison of two new techniques for the management of malignant central airway obstruction: argon plasma coagulation with mechanical tumor resection versus cryorecanalization. Surg Endosc 2018;32:1879-84.

16. Sandler AB, Nemunaitis J, Denham C, et al. Phase III trial of gemcitabine plus cisplatin versus cisplatin alone in patients with locally advanced or metastatic non-small-cell lung cancer. J Clin Oncol 2000;18:122-30.

17. Burris HA 3rd, Vogel CL, Castro D, et al. Intratumoral cisplatin/epinephrine-injectable gel as a palliative treatment for accessible solid tumors: a multicenter pilot study. Otolaryngol Head Neck Surg 1998;118:496-503.

18. Vogl TJ, Engelmann K, Mack MG, et al. CT-guided intratumoural administration of cisplatin/epinephrine gel

Cite this article as: Zhou Y, Gao Y, Zhang N, Li X, Wang H, Wang S, Liu J, Gao H, Wang H. Clinical effects of cisplatin plus recombinant human endostatin (rh-endostatin) intratumoral injection on malignant central airway obstruction: a retrospective analysis of 319 cases. J Thorac Dis 2021;13(2):11001105. doi: $10.21037 /$ jtd-20-1493 for treatment of malignant liver tumours. Br J Cancer 2002;86:524-9.

19. Monga SP, Wadleigh R, Adib H, et al. Endoscopic treatment of gastric cancer with intratumoral cisplatin/ epinephrine injectable gel: a case report. Gastrointest Endosc 1998;48:415-7.

20. Monga SP, Wadleigh R, Sharma A, et al. Intratumoral therapy of cisplatin/epinephrine injectable gel for palliation in patients with obstructive esophageal cancer. Am J Clin Oncol 2000;23:386-92.

21. Celikoglu F, Celikoglu SI, York AM, et al. Intratumoral administration of cisplatin through a bronchoscope followed by irradiation for treatment of inoperable non-small cell obstructive lung cancer. Lung Cancer 2006;51:225-36.

22. Mehta HJ, Begnaud A, Penley AM, et al. Restoration of Patency to Central Airways Occluded by Malignant Endobronchial Tumors Using Intratumoral Injection of Cisplatin. Ann Am Thorac Soc 2015;12:1345-50.

23. Zhou S, Zuo L, He X, et al. Efficacy and safety of rhendostatin (Endostar) combined with pemetrexed/ cisplatin followed by rh-endostatin plus pemetrexed maintenance in non-small cell lung cancer: A retrospective comparison with standard chemotherapy. Thorac Cancer 2018;9:1354-60.

24. An J, Lv W. Endostar (rh-endostatin) versus placebo in combination with vinorelbine plus cisplatin chemotherapy regimen in treatment of advanced non-small cell lung cancer: A meta-analysis. Thorac Cancer 2018;9:606-12.

25. Mudambi L, Miller R, Eapen GA. Malignant central airway obstruction. J Thorac Dis 2017;9:S1087-110.

26. Ost DE, Ernst A, Grosu HB, et al. Therapeutic bronchoscopy for malignant central airway obstruction: success rates and impact on dyspnea and quality of life. Chest 2015;147:1282-98.

27. Stratakos G, Gerovasili V, Dimitropoulos C, et al. Survival and Quality of Life Benefit after Endoscopic Management of Malignant Central Airway Obstruction. J Cancer 2016;7:794-802. 